\title{
A simulation analysis of factors influencing the flexibility of cellular manufacturing
}

\author{
M. DJASSEMI \\ Orfalea College of Business, California Polytechnic State University, San Luis Obispo, CA 93407, USA
}

\begin{abstract}
The performance of cellular manufacturing $(\mathrm{CM})$ systems in a variable demand and flexible workforce environment has been examined using simulation modelling. Discrepancies between academicians and practitioners' findings with respect to flexibility and uneven machine utilization in CM systems are discussed. The views of two parties were incorporated in simulation models to rectify the existing discrepancies. While the results of this study confirm the previous findings of academicians regarding the deterioration of the performance of $\mathrm{CM}$ in a variable product mix situation, it appears that those results may be significantly influenced by considering a flexible workforce. The simulation results show that the practice of using flexible crossed-trained operators can improve the flexibility of CM in dealing with an unstable demand and can reduce load imbalance inherent in machine dedication in manufacturing cells.
\end{abstract}

Keywords: Cellular manufacturing; Simulation

\section{Introduction}

The emergence of cellular manufacturing (CM) has dramatically changed batch type manufacturing. $\mathrm{CM}$ is an approach that helps build a variety of products with as little waste as possible. A cell is a group of work stations, machine tools arranged for a smooth flow, so a product can be processed progressively from one work station to another, without having to wait for a batch to be completed or requiring additional handling between operations (Olexa 2002). The processing of part-families in cellular manufacturing provides the advantages of the economy of scale in production without the formation of lots of large sizes (Burbidge 1992). For this reason, the full/ partial conversion from job shop to cellular manufacturing is a common practice in many discrete production systems (Wemmerlov and Hyer 1989).

The main transformation in the development of cellular manufacturing systems is the organization of production into dedicated robotics or manned machine cells, each one capable of fully processing one or more part-families. Such autonomous cells promise a much simpler flow of parts and faster manufacturing response than functionally oriented layouts.

Despite significant changes brought about by the introduction of cellular manufacturing, the controversy about the performance of $\mathrm{CM}$ systems remains 
unresolved. There is a fair amount of consensus in the literature that conversion of job shop systems to CM results in reduced flexibility and uneven machine utilization. In this context the terms 'flexibility' and/or 'routing flexibility', used in many of the CM studies, are commonly referred to as the availability of machines for part processing. Job shop systems are known to be more flexible in the sense that incoming parts can be processed by any machine from a group of similar machines grouped in one area. Such flexibility exists to a lesser degree in CM cells due to the configuring of manufacturing cells with a variety of dissimilar machines and dedicating them to process family of similar parts. Kanannan and Gosh (1996) compared cellular manufacturing layout to process layout under a wide range of conditions. Their results show that the cellular shop is rigid and inflexible and any advantages it holds cannot compensate for its lack of routing flexibility. Gupta and Tompkins (1982) used computer simulation to study routing flexibility in response to product variation and suggested that an alternate routing allows parts to search for the least congested machine of the required type. Morris and Tersine (1990) explored various approaches available for identifying machine cells and stated that the major flaw in cellular layouts is the reduction in flexibility that is inherent in machine dedication process. Finally, Gaither (1990) further argues that $\mathrm{CM}$ is relatively inflexible to change in product mix and volumes.

On the issue of machine utilization, Sassani (1990) notes that unbalanced workload distribution among cells creates problems in cellular layouts and attributes the source of problem to the tendency to set up permanent idealistic cells. Kannan and Gosh (1996) argue that traditional CM systems are faced with the particular problem that uneven loads between cells lead to low overall machine utilization. Indeed, several machine loading and scheduling approaches developed to date attempt to balance the workload among the machines and cells. For example, Mahmoodi et al. (1990) examined the impact of several order releasing assignment policies in a $\mathrm{CM}$ environment to reduce the load imbalance among machine cells. Likewise, a study by Okogbaa (1992) suggests the use of alternate routing balances workload for machines of the same type, thus the long queues in front of the very busy machines are shortened significantly.

While uneven machine utilization and lack of flexibility to product mix and volume are two common problems cited in much CM literature, a survey conducted by Hyer (1984) reported similar problems in CM user plants in the early 1980s when the concept of CM was relatively new for United States' manufacturing. However, in a more recent survey, Marsh et al. (1999) disputed the existence of such problems. The survey compared common research presumptions from academic literature to the practice of CM. The survey's findings, which are based on feedback from 14 firms with plants utilizing CM, reveal that these presumptions do not hold for the vast majority of $\mathrm{CM}$ users. First, it is said that practitioners are more concerned about labour utilization than machine or cell utilization. More importantly, the survey indicates that a common practice to balance the workload is through the use of cross-trained workers. It is also noted that moving workers is easier than moving machines or redistributing parts to cells. Second, the survey argues that none of the case sites exhibited a problem with reduced flexibility. In contrast to most $\mathrm{CM}$ research, which considers flexibility as routing flexibility, managers in industry are more interested in product volume and mix flexibility than routing flexibility and they maintain such flexibility by employing 
a flexible workforce. To this end, Wemmerlov and Hyer (1989) noted that moving cross-trained workers between cells adds considerable flexibility to the shop.

Finally, Shafer and Charnes (1997) used computer simulation models to investigate whether the important benefits of $\mathrm{CM}$ can counteract the loss in routing flexibility. The authors suggested several ways to extend their research, including research to investigate how firms might cope with the reduced routing flexibility resulting from machine dedication by using cross-trained workers, in effect substituting worker flexibility for routing flexibility. The authors concluded that research along these lines could help bridge the gap between the results reported in the academic literature and the achievement reported by practitioners. To rectify these existing discrepancies this study incorporates the views of two parties into simulation models. Flexible, cross-trained workers in manufacturing cells are used to assess the effect on $\mathrm{CM}$ performance in a variable demand environment.

\section{Methodology}

Simulation modelling has been effectively used in numerous studies to deal with the complexity of manufacturing systems (Seifoddini and Djassemi 1997, Sassani 1990). In this study, simulation is used to evaluate the performance of cellular manufacturing with the purpose of investigating the inconsistency between the performance of $\mathrm{CM}$ as envisioned by researchers and actual performance of $\mathrm{CM}$ as reported by practitioners. More specifically, the simulation models are designed to investigate the following disputed issues: Does the utilization of a cross-cellular workforce improve $\mathrm{CM}$ performance considering product mix and volume variability? Assuming that the utilization of a cross-cellular workforce results in improved CM performance, to what extent does CM constitute a more appropriate method for batch type manufacturing as compared to the traditional job shop system? Does the utilization of a cross-cellular workforce alleviate the problem of unbalanced workloads in CM cells? And, does such workforce flexibility play a role in counteracting the negative effects of uneven machine utilization in CM?

A paired- $t$ confidence interval test, which is known as an appropriate method for comparing alternative system configurations (Law and Kelton 1991) is employed to test the following two hypotheses at a $95 \%$ confidence level:

$\mathrm{H}_{\mathrm{o} 1}$ : No improvement can be made in performance of cellular manufacturing system when a cross-cellular multi-skilled workforce is employed.

In this study, cross-cellular, multi-skilled (CCMS) workers are defined as those workers who are trained to operate multiple machine types and that are not restricted to their own work cells. While this arrangement appears to provide more flexibility in a deterministic demand environment the impact on CM performance in a volatile demand environment is uncertain. If the $\mathrm{H}_{\mathrm{o} 1}$ hypothesis is rejected, then it can be concluded that the deployment of a cross-cellular workforce improves the flexibility of $\mathrm{CM}$ system in dealing with product mix and volume variation.

$\mathrm{H}_{\mathrm{O} 2}$ : No difference exists between the performance of $\mathrm{CM}$ and job shop in a variable demand environment when a cross-cellular multi-skilled workforce is employed. 
It is of interest to investigate which of these two types of manufacturing systems would benefit the most from a CCMS workforce plan in a variable demand environment, regardless of whether the plan seems to be more advantageous to a job shop environment. This could be due to the fact that workers in a CM environment are generally trained to be multi-functional. If this hypothesis is rejected it can be concluded that a CM system can outperform a job shop system in the presence of a flexible workforce and unstable demand.

An $F$ statistic, which is known as an appropriate method for testing hypotheses concerning variances of alternative system configurations (Miller et al. 1990), will be employed to test the following hypothesis at $\alpha=0.05$ level:

$\mathrm{H}_{\mathrm{o} 3}$ : The use of a cross-cellular multi-skilled workforce has no effect on the problem of uneven machine utilization in cellular manufacturing.

As noted earlier the problem of uneven machine utilization in a CM environment has been frequently reported in the literature. This problem stems from the configuration of CM cells with dissimilar and dedicated machines. In such an environment when a particular type of machine is busy, the incoming parts must wait in line since, in most cases, no other similar machine is available in the same cell. This can lead to overloading and/or over utilizing one machine and under utilizing others in the same cell. Such a problem can be further compounded by such factors as the unavailability of operators and demand volatility. Thus, it is desirable to investigate whether the use of a CCMS workforce can alleviate this uneven machine utilization. If the $\mathrm{H}_{\mathrm{o} 3}$ hypothesis is rejected, then it can be concluded that the use of CCMS operators would be beneficial to CM system in reducing uneven machine utilization.

A critical assumption included explicitly in the foregoing hypotheses is the variability of product mix and volume. It is fair to say that employing a deterministic data may impart some degree of predictability in the results of a simulation study. However, in real world situations, product mix and volume is a function of demand and it may well change as demand fluctuates. Ignoring this fact diminishes the validity of the simulation results. A variable demand pattern as Seifoddini (1990) noted may even adversely affect the performance of cellular manufacturing systems. In this context, the randomness nature of demand combined with inter-cellular workforce moves increases the complexity of the simulation models used in this study and indeed, poses a large degree of uncertainty in the outcome of the study.

\section{Experimental framework}

Two simulation models representing a cellular manufacturing system and its equivalent job shop configuration are developed to do the following:

- To generate demand, to assign parts to machine cells, to schedule the operations of part-families within each machine cell.

- To call workers for loading/unloading parts.

- To call workers for loading NC programs (in case of programmable machines).

- To call workers for loading/unloading tools and fixtures.

- To estimate the mean flow time, work-in-process inventories, and machine utilization. 
The environment and shop structure represents a hypothetical shop consisting of 18 part types and 15 machines. The job shop configuration consists of five functional departments, each containing two or four conventional and programmable machines with multiple tool holding capability. The equivalent cellular manufacturing system is formed using one of the available part family/machine cell formation methods known as rank order clustering (ROC) algorithm (King and Nakornchai 1980). The resulting machine-part matrix consisting of four part families and four machine cells is shown in figure 1. Parts are processed based on the sequence shown in the matrix for both systems under study.

Material handling in cellular manufacturing is not considered due to close proximity of machines within cells. In a job shop manual pallet jacks are used to move material from department to department at an average speed of 5 miles per hour. Loading and unloading times are uniformly distributed between 1 and 5 minutes.

The traditional performance measures such as mean flow time, work-in-process inventories, and machine utilization, are used.

The simulation modelling in this study is based on Taylor II simulation software (F\&H Simulations 1996) designed particularly for manufacturing and material handling applications. Only data in steady state condition are considered in estimating the true value of the performance measures. Based on the examination of plotted data, it is determined that the system can reach to a steady state condition after a transient period of 6 months. The data collected over that period are discarded. The simulation is run for 350 days, 8 hours a day, and 5 days a week beyond transient period.

\subsection{Set-up times}

The set-up time for a part on a machine is a function of its similarity to its predecessor part on the machine. The following coefficients are used to take into account this dependency:

1. 1.0: When the parts from two different part-families are loaded sequentially.

2. 0.5: When two parts from the same part-families are loaded sequentially.

3. 0.1: When two identical parts are loaded sequentially.

Since the comparative study of alternative shop configurations is involved, the set-up times and processing times are assumed to be deterministic to eliminate the effect of random variations on the results of study. The base set-up time is set equal to 0.25 fraction of processing time. This ratio is within the range used in the Kennan and Gosh (1996) and Morris and Tersine (1990) studies.

\subsection{The workforce}

Two types of workforce assignments were incorporated in the simulation models: single cell and multi-cell job assignments.

In single cell job assignment the operators are trained to set up and operate single machine types within a job shop department or multiple machines within cellular manufacturing shop. No inter-cellular or departmental switching is allowed under this type of job assignment. This feature of model mimics typical job assignment in real world manufacturing cells and departments. 


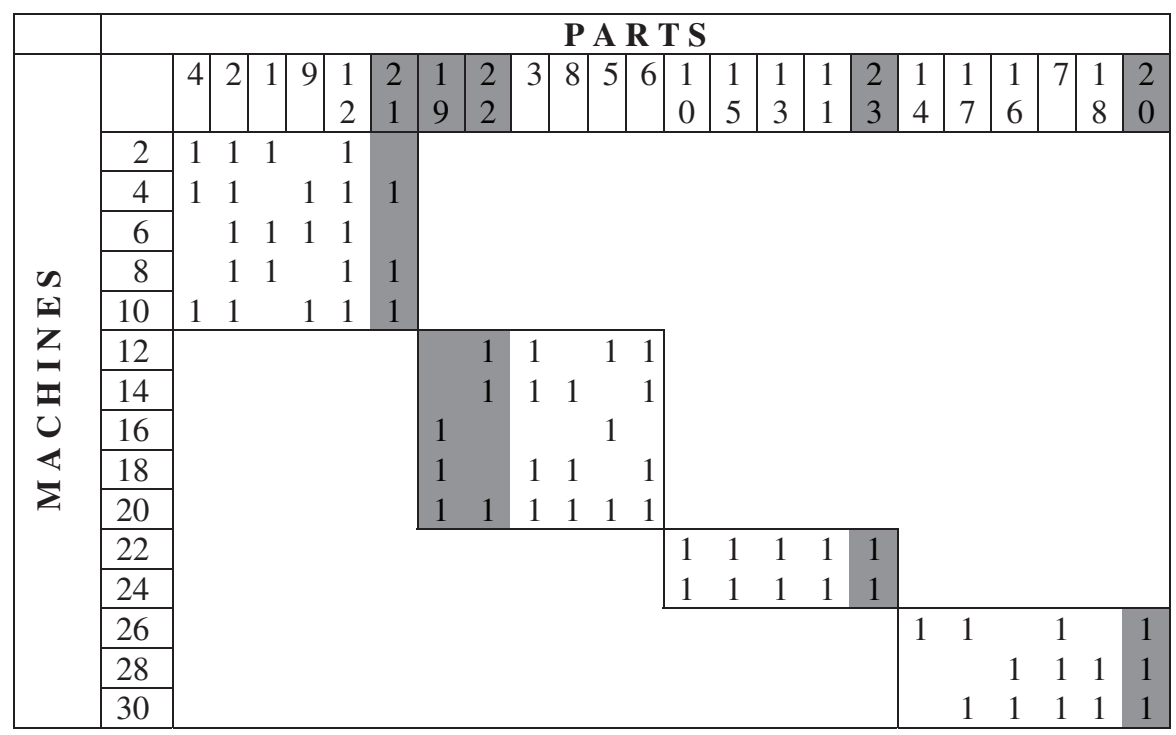

Figure 1. Machine-part matrix. Shaded columns represent part types added progressively to the simulation models.

This study examined a more flexible job assignment plan by considering a multi-cell job assignment in which CCMS operators are deployed without restricting them to their own work cell or department. Under this scenario operators are shifted back and forth as the workload varies in the different cells. Such flexibility is essential for testing hypotheses defined earlier. This is a practical approach and as pointed out in the introduction, the survey indicates that a number of CM user plants apply this approach to balance the workload in their manufacturing cells.

\subsection{Demand pattern}

Variation, in the product mix and volume, have been introduced through changes in part type. That is, the number of product types is increased incrementally one part type at a time until further increase yields no significant effect on the results of comparing the alternatives (see shaded columns in figure 1). Consideration of this factor in this study is based on real world application. As pointed out in the introduction, in contrast to most $\mathrm{CM}$ research, which considers flexibility as routing flexibility, managers in industry are more interested in product volume and mix flexibility.

It is assumed that the demand for parts is exponentially distributed. Upon arrival, the type of each part is determined and orders released to the shop floor for processing. Based on pilot simulation runs, it was determined that at a mean arrival time of 15 minutes no queue saturation will occur.

\section{Results and discussion}

To address the research questions the joint effects of workforce types and demand variations on cellular manufacturing and job shop models are examined in separate 
Table 1. Simulation results for mean flow time.

\begin{tabular}{|c|c|c|c|c|c|c|c|}
\hline \multirow{2}{*}{$\begin{array}{l}\text { Product } \\
\text { mix and } \\
\text { volume } \\
\text { changes }\end{array}$} & \multicolumn{4}{|c|}{ Mean flow time } & \multicolumn{3}{|c|}{$\Delta$ and $95 \% \mathrm{CI}$} \\
\hline & $\mathrm{JS}_{a}$ & $\mathrm{JS}_{b}$ & $\mathrm{CM}_{a}$ & $\mathrm{CM}_{b}$ & $\mathrm{CM}_{a}$ vs $\mathrm{CM}_{b}$ & $\mathrm{JS}_{a}$ vs $\mathrm{CM}_{a}$ & $\mathrm{JS}_{b}$ vs $\mathrm{CM}_{b}$ \\
\hline $0 \%$ & 200 & 156 & 191 & 147 & $41 \pm 2.5$ & $8.5 \pm 1.2$ & $4.5 \pm 09$ \\
\hline $5 \%$ & 216 & 118 & 214 & 112 & $98 \pm 3.1$ & $1.4 \pm 06$ & $6.1 \pm 1.1$ \\
\hline $10 \%$ & 226 & 89 & 382 & 148 & $227 \pm 4.2$ & $153 \pm 7.4$ & $57 \pm 3.3$ \\
\hline $15 \%$ & 398 & 190 & 472 & 171 & $304 \pm 9.5$ & $71 \pm 3.6$ & $18 \pm 1.08$ \\
\hline $20 \%$ & 510 & 217 & 560 & 193 & $363 \pm 11.5$ & $48 \pm 2.6$ & $22.5 \pm 1.2$ \\
\hline $25 \%$ & 550 & 240 & 610 & 202 & $414 \pm 19.4$ & $55 \pm 4.1$ & $36.6 \pm 2.1$ \\
\hline
\end{tabular}

$\mathrm{CM}_{a}$, no cross-cellular workforce; $\mathrm{CM}_{b}$, with CCMS workforce; $\mathrm{JS}_{a}$, no cross-cellular workforce; $\mathrm{JS}_{b}$, with CCMS workforce.

Table 2. Simulation results for mean work-in process inventories.

\begin{tabular}{|c|c|c|c|c|c|c|c|}
\hline \multirow{2}{*}{$\begin{array}{l}\text { Product } \\
\text { mix and } \\
\text { volume } \\
\text { changes }\end{array}$} & \multicolumn{4}{|c|}{ Mean work-in-process } & \multicolumn{3}{|c|}{$\Delta$ and $95 \% \mathrm{CI}$} \\
\hline & $\mathrm{JS}_{a}$ & $\mathrm{JS}_{b}$ & $\mathrm{CM}_{a}$ & $\mathrm{CM}_{b}$ & $\mathrm{CM}_{a}$ vs $\mathrm{CM}_{b}$ & $\mathrm{JS}_{a}$ vs $\mathrm{CM}_{a}$ & $\mathrm{JS}_{b}$ vs $\mathrm{CM}_{b}$ \\
\hline $0 \%$ & 23 & 14 & 18 & 10 & $7.5 \pm 0.5$ & $4.5 \pm 8$ & $3.6 \pm 0.07$ \\
\hline $5 \%$ & 20 & 12 & 13 & 11 & $2.1 \pm 0.04$ & $6.2 \pm 0.4$ & $0.8 \pm 0.03$ \\
\hline $10 \%$ & 27 & 17 & 24 & 15 & $8.7 \pm 0.07$ & $3.1 \pm 0.05$ & $1.8 \pm 0.06$ \\
\hline $15 \%$ & 55 & 25 & 22 & 16 & $8.4 \pm 1.1$ & $27 \pm 2.7$ & $9.1 \pm 0.11$ \\
\hline $20 \%$ & 62 & 23 & 33 & 18 & $14.1 \pm 2.2$ & $28 \pm 3.2$ & $4.7 \pm 0.85$ \\
\hline $25 \%$ & 74 & 32 & 34 & 24 & $9.6 \pm 1.2$ & $29 \pm 2.8$ & $10.8 \pm 0.65$ \\
\hline
\end{tabular}

$\mathrm{CM}_{a}$, no cross-cellular workforce; $\mathrm{CM}_{b}$, with CCMS workforce; $\mathrm{JS}_{a}$, no cross-cellular workforce; $\mathrm{JS}_{b}$, with CCMS workforce.

simulation experiments. Estimates of mean flow times and work-in-process inventories for job shop and CM systems generated by a simulation model are given in table 1 and table 2 .

To create a variable product mix condition the number of product types is increased incrementally one part type at a time. The shaded area in figure 1 reflects the addition of parts number $21,19,22,23$ and 20 to various cells. As can be seen in table 1 , the addition of the first part to product mix changes the mix by about $5 \%$ while the addition of last part (part number 20) would change the mix by about $25 \%$. Further increase in product mix did not yield a significant difference in the comparison results for the two systems under study. The simulation results indicate that a change in percentage of product mix within a 0 to $25 \%$ range leads to deterioration in performance of both systems, but it appears that the CM system is more sensitive to this change. The mean flow time for the job shop system $\left(\mathrm{JS}_{a}\right)$ increased from 200 to 550 , an increase of $150 \%$. The corresponding change in mean flow time of $\mathrm{CM}$ system $\left(\mathrm{CM}_{a}\right)$ is more than $200 \%$. These results concur with the previous findings of Seiffodini and Djassemi (1997). However, it is desirable to find how the use of a flexible CCMS workforce in a variable demand environment would influence the performance of the two alternative manufacturing systems.

First, the simulation model for the $\mathrm{CM}$ system is tested to investigate whether any improvement can be made using a flexible workforce. As can be seen 
from table 1 and table 2, the mean flow time has improved when a flexible cross-trained workers scheme $\left(\mathrm{CM}_{b}\right)$ is implemented. It is also shown that the improvement level is more significant at higher levels of product mix and volume changes. In other words, the presence of a cross-trained workforce has positively affected the mean flow time. This is because by allowing the workers to move from an area with lower workload to the cells with higher workload, jobs spend less time on the floor. This strategy was particularly effective when demand increased by 20 to $25 \%$. The mean flow time increased from a high of 610 minutes at $25 \%$ demand change to a low of 202 minutes after inter-cellular operator transfer was allowed. On the basis of paired- $t$ test statistics, null hypothesis of no significant improvement in performance of cellular manufacturing system, under two alternative workforce types $\left(\mathrm{CM}_{a}\right.$ versus $\left.\mathrm{CM}_{b}\right)$, was rejected at a 0.05 level of significance.

Second, the simulation models were used to compare the performances of the two alternative manufacturing systems $\left(\mathrm{JS}_{b}\right.$ versus $\left.\mathrm{CM}_{b}\right)$. From data shown in table 1 and table 2 it appears that job shop system benefits from a flexible CCMS workforce not as much as CM system. This can be explained by taking into consideration the uneven workload problem in manufacturing cells resulting from machine dedication (Okogbaa 1992). It is reasonable to conclude that shifting workers from one cell to another would expedite the loading/ unloading of a highly busy machine in another cell. The results also reveal that using a flexible CCMS labour maintains the superiority of the CM system even beyond the $20 \%$ change in product mix. This shows a contrast with respect to Seiffodini and Djassemi's paper, which concluded that beyond a $13 \%$ increase in product mix, CM system is no longer desirable and job shop has a superior performance.

The null hypotheses $\left(\mathrm{H}_{\mathrm{o} 1}, \mathrm{H}_{\mathrm{O} 2}\right)$ were both rejected in five out of the six levels of demand at the 0.05 level of significance. The only demand level at which these hypotheses was not rejected was at the $10 \%$ level, possibly due to the randomness nature of input data.

A graphical comparison of performances of cellular manufacturing and job shop systems in terms of mean flow time as a function of product mix variation before and after applying the CCMS workforce scenario is given in figure 2 .

One objective of this study was to investigate whether the use of CCMS workers can counteract the problems of uneven machine utilization and imbalance workload in manufacturing cells. This approach has been implemented in some CM user plants but has not been sufficiently evaluated in academic simulation studies.

The estimates of mean, standard deviations and range of machine utilization are generated and tabulated in table 3. It is noticeable that for different levels of demand, the standard deviation and range of mean machine utilization were reduced when the operator exchange among work cells was allowed. On the basis of $\mathrm{F}$ statistics, the null hypothesis $\left(\mathrm{H}_{\mathrm{o} 3}\right)$ of no significant changes in reducing machine utilization variation was rejected at a 0.05 level of significance. From graphical results in figure 3 it appears that the uneven machine utilization in cellular manufacturing system, $\left(\mathrm{CM}_{\mathrm{b}}\right.$-STD and $\left.\mathrm{CM}_{\mathrm{b}_{-}} \mathrm{R}\right)$ becomes less pronounced with the presence of a flexible workforce. This result verifies the effectiveness of the practice of using 
Flow time vs. system flexibility

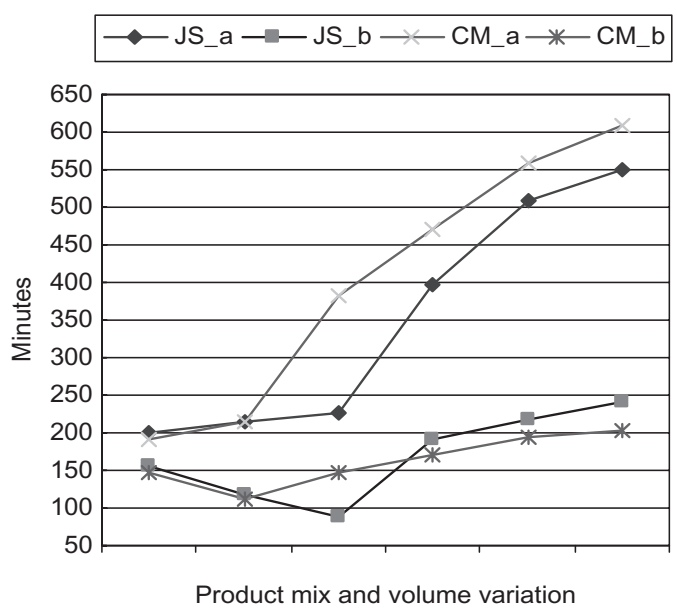

Figure 2. Mean flow time vs product mix variation for job shop and cellular manufacturing system.

Table 3. Simulation results for workload variation in the cellular manufacturing system.

\begin{tabular}{|c|c|c|c|c|c|c|c|}
\hline \multirow{2}{*}{$\begin{array}{l}\text { Product mix/volume } \\
\text { changes }\end{array}$} & \multicolumn{3}{|c|}{$\mathrm{CM}_{a}$} & \multicolumn{3}{|c|}{$\mathrm{CM}_{b}$} & \multirow{2}{*}{$\begin{array}{l}\mathrm{F} \text { statistics } \mathrm{n} 1=15, \\
\mathrm{n} 2=15 \mathrm{~F}_{0.05}=2.4 \\
\mathrm{~F}=\mathrm{S}_{\mathrm{CM} a}^{2} / \mathrm{S}_{\mathrm{CM} b}^{2}\end{array}$} \\
\hline & Mean & STD & Range & Mean & STD & Range & \\
\hline $0 \%$ & $70 \%$ & $17 \%$ & $80 \%$ & $73 \%$ & $14 \%$ & $72 \%$ & 1.47 \\
\hline $5 \%$ & $72 \%$ & $18 \%$ & $69 \%$ & $73 \%$ & $15 \%$ & $65 \%$ & 1.44 \\
\hline $10 \%$ & $75 \%$ & $23 \%$ & $73 \%$ & $68 \%$ & $17 \%$ & $70 \%$ & 1.83 \\
\hline $15 \%$ & $79 \%$ & $21 \%$ & $77 \%$ & $76 \%$ & $17 \%$ & $69 \%$ & 1.52 \\
\hline $20 \%$ & $78 \%$ & $21 \%$ & $56 \%$ & $79 \%$ & $18 \%$ & $73 \%$ & 1.36 \\
\hline $25 \%$ & $80 \%$ & $22 \%$ & $79 \%$ & $80 \%$ & $18 \%$ & $71 \%$ & 1.67 \\
\hline
\end{tabular}

$\mathrm{CM}_{a}$, no cross-cellular workforce; $\mathrm{CM}_{b}$, with CCMS workforce.

\section{Machine workload variation}



Figure 3. Standard deviation and range for the cellular manufacturing system. 
crossed-trained workers to balance the workloads as reported in the Marsh et al. (1999) paper.

\section{Conclusion}

Two important observations can be made with respect to the results of this simulation study. First, the flexibility of cellular manufacturing systems can be substantially improved by deploying a multi-skilled, inter-cellular workforce. Such flexibility may maintain the superiority of the cellular manufacturing system to the equivalent job shop system, even at a higher level of product mix and volume changes than those reported in Seifoddini and Djassemi's paper. Second, the results were mainly in favour of the idea of managers in industry using a flexible workforce to minimize the problem of uneven workload in CM and to increase the flexibility of CM.

It appears that the consideration of using crossed-trained and intercellular workers as it is applied in some CM user plants could influence the results of comparative studies conducted by academicians in the past in favour of cellular manufacturing systems. The practice of using a flexible workforce definitely has sufficient merit to be considered in cellular manufacturing studies. However, generating a multi-skilled workforce involves extensive operator training. Care must be taken in future studies to limit the number of operations that an operator is expected to learn. As the Wemmerlov and Johnson (1997) survey indicates there is a practical limit to the number of distinct operations that workers can handle effectively.

\section{References}

Burbidge, J., Change of group technology: process organization is obsolete. Int. J. Prod. Res., 1992, 30, 1209-1220.

King, J.R. and Nakornchai,V., Machine-component grouping in production flow analysis: an approach using rank order clustering algorithm. Int. J. Prod. Res., 1980, 18, 213-237.

Miller, I.R., Freund, J.E. and Johnson, R., Probability and Statistics for Engineers, 1990 (Prentice-Hall: NJ).

Gaither, N., From job shops to manufacturing cells. Prod. Invent. Manage. J., 1990, 31, 33-42.

Gupta, R.M. and Tompkins, J.A., An examination of dynamic behavior of part-families group technology. Int. J. Prod. Res., 1982, 20, 73-86.

Hyer, N.L., The potential of group technology for U.S. manufacturing. J. Op. Manage., 1984, 4, 183-202.

Kannan, V.R. and Ghosh, S., A virtual cellular manufacturing approach to batch production. Dec. Sci., 1996, 27, 519-539.

Law, A.M. and Kelton, W.D., Simulation Modelling and Analysis, 1991 (McGraw Hill: New York, NY).

Mahmoodi, F., Dooley, K.J. and Starr, P.J., An evaluation of order releasing and due date assignment heuristics in a cellular manufacturing system. J. Op. Manage., 1990, 9, 548-572.

Marsh, R.F., Shafer, S. and Meredith, J.R., A comparison of cellular manufacturing research presumptions with practice. Int. J. Prod. Res., 1999, 37, 3119-3138.

Morris, J.S. and Tersine, R.J., A simulation analysis of factors influencing the attractiveness of group technology cellular layouts. Manage. Sci., 1990, 36, 1567-1578. 
Okogbaa, O.G., Chen, M., Changchit, C. and Shell, R.L., Manufacturing system cell formation and evaluation using a new inter-cell flow reduction heuristic. Int. J. Prod. Res., 1992, 30, 1101-1118.

Olexa, R., When cells make sense. Manu. Eng., 2002, 128, 45-51.

Sassani, F., A simulation study on performance improvement of group technology cells. Int. $J$. Prod. Res., 1990, 28, 293-300.

Seifoddini, H. and Djassemi, M., Determination of a flexibility range for cellular manufacturing systems under product mix variations. Int. J. Prod. Res., 1997, 35, 3349-3366.

Seifoddini, H., A probabilistic model for machine cell formation. J. Manufact. Syst., 1990, 9, 69-75.

Shafer, S. and Charnes, J. M., Offsetting lower routeing flexibility in cellular manufacturing due to machine dedication. Int. J. Prod. Res., 1997, 35, 551-567.

F\&H Simulations, TAYLOR II for Windows Simulation Software, 1996, The Netherlands.

Wemmerlov, U. and Hyer, N.L., Cellular manufacturing in the US industry: a survey of users. Int. J. Prod. Res., 1989, 27, 1151-1530.

Wemmerlov, U. and Johnson, D.J., Cellular manufacturing at 46 user plants: implementation experiences and performance improvements. Int. J. Prod. Res., 1997, 35, 29-49. 